\title{
Psiquiatria, cultura e sociedade no México
}

\section{Psychiatry, culture and society in Mexico}

\author{
Ede Cerqueira ${ }^{i}$ \\ 'Casa de Oswaldo Cruz/Fiocruz. \\ Rio de Janeiro - RJ - Brasil \\ orcid.org/0000-0003-1741-4763 \\ dy_cbc@hotmail.com
}

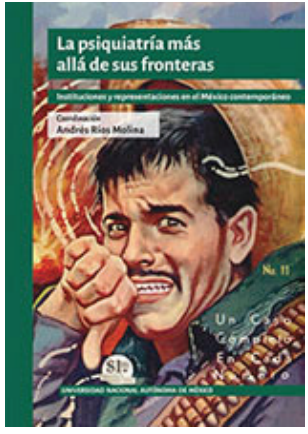

RÍOS MOLINA, Andrés (Coord.). La psiquiatría más allá de sus fronteras: instituciones y representaciones en el México contemporáneo. Ciudad de México: Universidad Nacional Autónoma de México. 2017. 312p.
O livro La psiquiatría más allá de sus fronteras: instituciones y representaciones en el México contemporáneo, como o próprio título indica, tem como objetivo explorar as formas como a psiquiatria se relacionou com os campos sociais, políticos e culturais no México, ultrapassando as fronteiras da clínica. Coordenada por Andrés Ríos Molina (2017), a obra reúne autores que, a partir de metodologias e aportes teóricos diversos, procuram explorar as relações estabelecidas entre sociedade e psiquiatria sob o viés da história cultural. Para desenvolver esse tipo de análise, eles partem de um primoroso, variado e inovador conjunto de fontes, que envolve desde planos educativos, correspondência administrativa, cartografias, imagens publicitárias, fotografias, fotonovelas até comics.

Os cinco capítulos que compõem a obra se estruturam em torno de um duplo viés historiográfico, privilegiando, por um lado, o estudo das instituições educacionais, médicas e governamentais onde a psiquiatria desempenhou um papel relevante e, por outro, as representações culturais sobre a loucura, tanto no âmbito do discurso como da prática, disseminadas em múltiplos espaços da Cidade do México. Nesses capítulos são apresentados outros atores sociais, além dos médicos e psiquiatras, como pedagogos, administradores públicos, empresários e fotógrafos, entre outros, que também se preocuparam em alguma medida com questões relacionadas às enfermidades mentais.

Daniel Vicencio, no primeiro capítulo, estuda os últimos anos de funcionamento do Manicômio Geral de La Castañeda, fundado em 1910 na região de Mixcoac, até seu fechamento e demolição em 1968. O autor procura demonstrar, em oposição à historiografia sobre o tema, que a "Operação Castañeda", que possibilitou o fechamento do hospício, longe de ser apenas uma iniciativa governamental amparada pelas teorias médicas, foi um processo que envolveu outros atores - empreiteiros e administradores públicos -, cuja participação foi determinante, mobilizando interesses médicos, econômicos e políticos. Já o segundo capítulo 
trata do desenvolvimento e institucionalização da psiquiatria infantil e da educação especial no México, a partir do estudo de duas instituições psiquiátricas criadas pela Secretaria de Educação Pública na década de 1920, o Instituto Médico Pedagógico Parque Lira e a Clínica de Conduta. Nesse capítulo, a autora, Ximena López Carrilo, analisa como se desenvolveram as relações entre a medicina mental infantil e as escolas, destacando as formas como o contexto institucional educativo definiu as práticas e o olhar da psiquiatria clínica sobre a infância. José Antonio Maya González, no capítulo seguinte, analisa as representações sociais sobre a epilepsia presentes tanto na imprensa como na publicidade médica, em comparação ao discurso desenvolvido pela medicina psiquiátrica. O autor observa que houve uma variação considerável do olhar sobre os indivíduos acometidos pela epilepsia, na Cidade do México, entre o final do século XIX e início do XX, que dependeu do lugar social em que as representações sobre eles foram elaboradas. Na sequência, Rebeca Monroy Nasr trabalha com a análise de fotografias produzidas sobre o Manicômio La Castañeda até seu fechamento, incluindo também imagens de algumas das instituições hospitalares que o substituíram. A autora observa, a partir desse rico material, como as imagens produzidas serviram a propósitos vários ao longo do tempo, influenciadas pelas mudanças políticas, institucionais e pelo olhar do fotógrafo. No último capítulo, Andrés Ríos Molina utiliza fotonovelas e comics, publicados na Cidade do México entre 1963 e 1979, como fontes para desenvolver uma análise das representações da loucura nesse tipo de produção cultural.

Os autores participantes dessa obra coletiva apresentam uma significativa contribuição para os estudos culturais em história da psiquiatria, tanto pelo amplo conjunto de fontes levantadas como pelas relevantes análises desenvolvidas a partir delas. Essas fontes, que remetem a produções desenvolvidas em outros âmbitos que não o estritamente vinculado à ciência médica psiquiátrica, apresentam uma polifonia de discursos produzidos sobre a loucura e os cuidados com ela por atores sociais de campos como a imprensa, a educação, a política e a administração local, demonstrando o quanto as vozes externas ao hospício influenciavam seu funcionamento. Em alguns momentos, no entanto, os autores acentuam a separação entre o campo psiquiátrico e o contexto cultural e social mais amplo, como se cada um desses atores sociais - médicos e não médicos - fossem produtores de discursos singulares e independentes que não se influenciassem mutuamente. Essa separação não se justifica se considerarmos a ciência psiquiátrica um empreendimento social que deve ser analisado inserido nesse contexto, conforme trabalhos mais recentes sobre a história das ciências têm mostrado. Concluindo, reafirmo a significativa contribuição da obra para a historiografia da psiquiatria, uma vez que incentiva a ampliação e diversificação do escopo de fontes utilizadas, assim como dos temas e atores sociais eleitos como objetos de análise nesse campo do conhecimento.

\section{REFERÊNCIAS}

RÍOS MOLINA, Andrés.

La psiquiatría más allá de sus fronteras: instituciones y representaciones en el México contemporáneo.
Ciudad de México: Universidad Nacional Autónoma de México. 2017. 